Original Research Article

\title{
Assessment of immune response to Hepatitis B vaccine by estimation of anti - HBs antibody titer among immunized health care workers
}

\author{
Badave G.K. ${ }^{1}$, Puneriya P. ${ }^{2}$ \\ ${ }^{1}$ Dr. Gitanjali Kailas Badave: Associate Professor, Microbiology, Mahavir Institute of Medical Sciences, Vikarabad, \\ Telangana, ${ }^{2}$ Ms Priyanka Puneriya, Third year MBBS student, Mahavir Institute of Medical Sciences, Vikarabad, \\ Telangana, India.
}

Corresponding Author- Dr. Gitanjali Kailas Badave, Associate Professor, Address: Department of Microbiology, Mahavir Institute of Medical Sciences, Vikarabad, Telangana, India. Email: badve.gitanjali@gmail.com

\begin{abstract}
Background: Hepatitis B vaccination is recommended for all health care workers as they constitute a high-risk group for acquiring blood borne hepatitis B infection. Anti HBs level $\geq 10 \mathrm{mIU} / \mathrm{ml}$ at any time after vaccination is considered as a marker of sustained immunity, which provides protection against infection. Poor sero-protection rates to hepatitis B vaccine are recognized and some individuals do not develop sufficient levels of anti-HBs antibodies. Hence, it is necessary to identify the individuals who are non-protective responders to vaccination. With this background, the present study was undertaken to determine immune response to hepatitis B vaccine amongst the health care workers. Material and Methods: The present cross-sectional study included 200 health care workers in a tertiary teaching hospital, who were immunized with three complete doses of hepatitis B vaccine. Quantitative determination of anti HBs levels was done by ELISA. The effect of gender, age, smoking, body mass index and duration after immunization on antibody levels were analyzed. Results: The association of anti-HBs status and gender was not statistically significant. Increase in age leads to decline of anti-HBs protective responders. Smoking and higher body mass index are significantly associated with less anti HBs titers $(<10 \mathrm{mIU} / \mathrm{ml})$. Conclusion: The highest number of protective responders is seen in initial 5 years post vaccination duration and least protective responders are observed in $>10$ years post vaccination duration, indicating decline in antibody response over a period of time.
\end{abstract}

Keywords: Hepatitis B vaccine, Health care worker, Anti-HBs titer, ELISA, CDC

\section{Introduction}

Hepatitis B virus (HBV) prevalence amongst the general population in India ranges from 2 to $8 \%$, thus categorized as intermediate endemic zone for HBV [1] The risk of contracting HBV by health care workers (HCW) is four-times greater than that of general population [2]. Blood infected with HBV carries the highest HBV load; making blood borne transmission as the most important mode in health-care setting [3]. Previous studies among HCWs in India had shown a high prevalence of Hepatitis B surface antigen (HBsAg) positivity $(2-10 \%)[4,5]$ whereas recent studies have shown a relatively low prevalence $(0.4-2 \%)[6,7]$.

Introduction of HBV vaccine in India was pilot-tested and later expanded to the entire country in 2011-12 [ 8] Hepatitis B vaccine is safe, provides long lasting

Manuscript received: $10^{\text {th }}$ October 2019

Reviewed: $20^{\text {th }}$ October 2019

Author Corrected: $26^{\text {th }}$ October 2019

Accepted for Publication: $30^{\text {th }}$ October 2019 immunity and also indirectly protects against hepatocellular carcinoma $[9,10]$. Reports from India indicate that only $16-60 \%$ of HCWs have received complete HBV immunization. Paramedical staff has a greater risk of $\mathrm{HBV}$ transmission as occupational hazard, also the adherence of universal safety precautions is neglected among HCWs in developing countries $[11,12]$.

Centre for Disease Control and Prevention (CDC) has recommended that all $\mathrm{HCW}$ should receive Hepatitis $\mathrm{B}$ vaccination at 0,1 , and 6 months, administered intramuscularly [13]. Immunocompetent individuals having vaccine-induced anti-HBs titer of $\geq 10 \mathrm{mIU} / \mathrm{mL}$ after 1-2 months of complete dose of Hepatitis B vaccine are considered as seroprotected [14]. Vaccine induced seroprotection is a useful surrogate marker of vaccine efficacy [15]. Post vaccination seroprotection is achieved in approximately $95 \%$ of healthy individuals

Pathology Update: Tropical Journal of Pathology \& Microbiology Available online at: www.medresearch.in 807 | P a g e 


\section{Original Research Article}

[16]. All HCWs, who are recently vaccinated should undergo anti-HBs testing, performed 1-2 months after administration of the last dose of the vaccine. Age, gender, obesity, smoking, immunity, and genetic factors may be responsible for reduced immune response to vaccination as documented in various Indian research studies $[17,18]$. An anti-HBs titer less than $10 \mathrm{mIU} / \mathrm{ml}$ is regarded as nonresponsive, levels between 10 and $100 \mathrm{mIU} / \mathrm{ml}$ are considered as hypo response and more than $100 \mathrm{mIU} / \mathrm{ml}$ is considered as high level of immunity following vaccination.

Levels more than $10 \mathrm{mIU} / \mathrm{ml}$ at any time after vaccination are considered as a marker of sustained immunity which provides protection against infection [14]. While the protective level of anti-HBs after primary vaccination has been shown to be $10 \mathrm{mIU} / \mathrm{mL}$ but the level of antibody necessary to provide long-term protect against HBV infection is still unknown [19].

The vaccination derived anti-HBs titers vanish over a period of time and the need for booster doses has long been a matter of argument. It seems reasonable that high-risk populations like HCWs may need boosters when their anti-HBs fall below the protective level.

According to CDC and the World Health Organization (WHO), there is no need to give boosters to individuals who acquired anti-HBs levels of $\geq 10 \mathrm{mIU} / \mathrm{ml}$ after completion of the HB vaccine schedule [14]. US Public Health Service do not recommend booster dose in $\mathrm{HCW}$ after completion of primary immunization with protective level of anti-HBs. However, HBV booster is recommended in immuno-compromised $\mathrm{HCWs}$ to maintain anti-HBs levels of more than $10 \mathrm{mIU} / \mathrm{ml}$ [20].

Poor seroprotection rates to hepatitis B vaccine are documented in subjects of older age group, Body Mass Index $(\mathrm{BMI}) \geq 25$, smokers and poor nutritional status $[17,18]$.This makes it necessary to identify the individuals who are hypo responsive to vaccination thus taking necessary actions. The need for the present study is becoming increasingly important in Indian scenario to create awareness and ensure complete protection from Hepatitis B infection in high risk individuals particularly among health care workers. With this background the present study was undertaken to evaluate anti-HBs antibody levels among immunized health care workers in a teaching hospital.

\section{Aims and Objectives}

1. Estimation of anti-HBs antibody titer by Enzyme Linked Immune Sorbent Assay (ELISA) test in immunized health care workers.
2. Assessment of variation of anti-HBS titers with factors like gender, age, smoking, body mass index and post immunization duration.

\section{Material and Methods}

Place of study: Mahavir Institute of Medical Sciences, Vikarabad, Telangana State.

Type of study: Cross sectional

Study population: Health care workers in tertiary care hospital

\section{Inclusion criteria}

Health care workers (doctors, staff nurses, technicians) in tertiary care hospital who have been immunized against Hepatitis B with 3 complete doses.

\section{Exclusion criteria}

1. Health care workers in tertiary care hospital who are not immunized against Hepatitis B or immunized without completion of full course of vaccination.

2. Health care workers who are positive for HBsAg.

The current study included 200 healthcare workers who received full course of hepatitis $\mathrm{B}$ vaccine. Ethical clearance from the Institutional Ethical Committee and Informed consent from all individuals was obtained for the study. The demographic details like age, gender, height, weight, personal habits, medical history, and details of Hepatitis B immunization were recorded for each individual in case record form.

Under strict aseptic precautions, $3 \mathrm{ml}$ of venous blood was collected by venipuncture from all subjects. Serum separation was performed by centrifugation of the blood sample at $2000 \mathrm{rpm}$ for 20 minutes. Serum thus separated was stored at $-20^{\circ} \mathrm{C}$ until anti-HBs test was undertaken. Commercially available HBsAb ELISA kit for quantitative determination of antibodies to Hepatitis B surface antigen, manufactured by DIA. PRO diagnostic (Italy) was used for quantitative assay of anti-HBs. ELISA was performed as per the manufacturer's instructions.

As per the assay procedure for quantitative analysis, $50 \mu 1$ of specimen diluent was added in all the microwells except the wells for blanking. Further, $100 \mu \mathrm{l}$ of all the calibrators $(0,10,50,100,250 \mathrm{mIU} / \mathrm{ml})$ and 100 $\mu \mathrm{l}$ of control serum in duplicate was dispensed in the corresponding micro-wells as per the manufacturer protocol. The micro-plate was incubated at $37^{\circ} \mathrm{C}$ for 60 minutes. Later five washing cycles (aspiration and dispensation of washing solution) were performed using wash buffer concentrate (350 $\mu \mathrm{l} /$ well). Then $100 \mu \mathrm{l}$ of

Pathology Update: Tropical Journal of Pathology \& Microbiology Available online at: www.medresearch.in 808 | P a g e 


\section{Original Research Article}

enzyme conjugate was added in all the micro-wells except blank micro-wells. The micro-plate was again incubated at $37^{\circ} \mathrm{C}$ for 60 minutes followed by washing cycles as done before. Then $100 \mu \mathrm{l}$ of chromogen substrate (tetramethyl benzidine and hydrogen peroxide) was added in all the wells including blank wells. The micro-plate was again incubated at room temperature for 20 minutes followed by addition of 100 $\mu 1$ of sulphuric acid in each well. The color intensity was measured with micro-plate reader at $450 \mathrm{~nm}$ and $620 \mathrm{~nm}$. Anti-HBs antibodies were quantitated by means of standard curve calibrated against WHO reference preparation (1977) with concentrations of 0 , $10,50,100,250 \mathrm{mIU} / \mathrm{ml}$. As per the results of post HBV immunization titer, health care workers were classified as follows:

1. A protective responder is a person with levels of anti$\mathrm{HBs} \geq 10 \mathrm{mlU} / \mathrm{ml}$

2. A non-protective responder is a person with levels of anti-HBs $<10 \mathrm{mlU} / \mathrm{ml}$.
Note:protective responder and non protective responder terminology used in the present study is strictly based on above mentioned anti HBs titer after primary series of complete hepatitis $\mathrm{B}$ vaccination.

Whereas, as per CDC guidelines subjects with anti-HBs level $<10 \mathrm{mlU} / \mathrm{ml}$ after primary series of complete vaccination are advised to repeat the complete series of vaccination again.

Even after second series of complete vaccination, if subject continues to have anti-HBs level $<10 \mathrm{mlU} / \mathrm{ml}$, then they are considered as non-responders to vaccination.

Statistical analysis: Analysis of results was carried out by Statistical Package for the Social Sciences (SPSS). Chi-square test was used for significance of difference in various groups. $\mathrm{p}$ value $<0.05$ was considered significant.

\section{Results}

A total of 200 subjects participated, of which $160(80 \%)$ were protective responders and $40(20 \%)$ were non protective responders, post immunization. Anti-HBs status in relation to gender is as mentioned in Table 1.

Table-1: Gender and anti-HBs status

\begin{tabular}{|c|c|c|c|}
\hline Anti-HBs status & Male & Female & Total \\
\hline Protective responder & $88(75.9 \%)$ & $72(85.8 \%)$ & $160(80 \%)$ \\
\hline Non-protective responder & $28(24.1 \%)$ & $12(14.2 \%)$ & $40(20 \%)$ \\
\hline Total & $116(100 \%)$ & $84(100 \%)$ & $200(100 \%)$ \\
\hline
\end{tabular}

$\mathrm{p}$ value by Chi square test is 0.08 (not significant as $\mathrm{P}$ value is more than 0.05 )

Although the percentage of female protective responders was greater $(85.8 \%)$ compared to male protective responders (75.9\%), the association of anti-HBs status and gender was not statistically significant ( $\mathrm{p}$ value 0.08 ). As seen in Figure1 , increase in age leads to decline of anti-HBs protective responders. The lowest number of non-protective responders $(03 / 40)$ is seen in age group less than 20 years. Whereas, highest number of non-protective responders $(18 / 40)$ is seen in age group of more than 60 year.

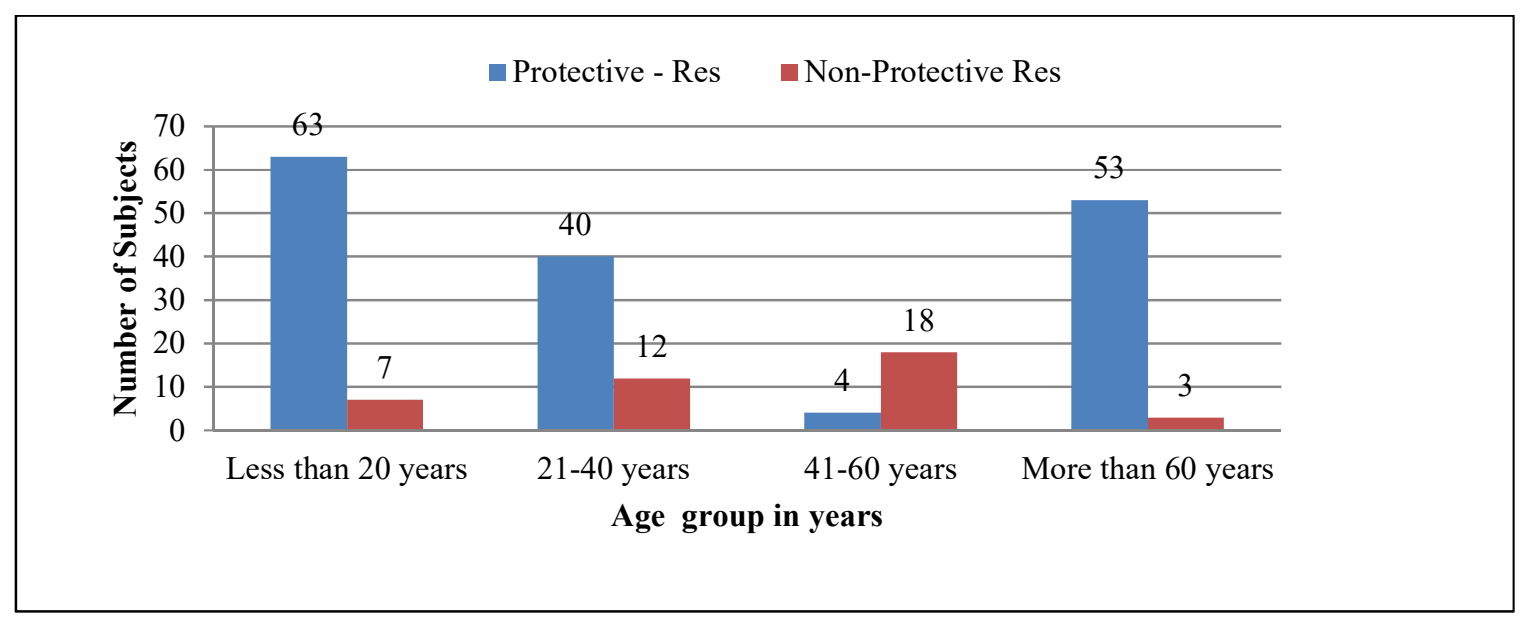

Figure-1: Age wise distribution of protective responders/non-protective responders of anti-HBs status.

Pathology Update: Tropical Journal of Pathology \& Microbiology Available online at: www.medresearch.in 809 | P a g e 
Original Research Article

Table-2 shows comparison of anti-HBs status among smokers and non-smokers. Smokers has less protective responders as compare to non-smokers and this is statistically significant ( $\mathrm{p}$ value less than 0.0001 ).

Table-2: Smoking and anti-HBs status

\begin{tabular}{|c|c|c|c|}
\hline Anti-HBs status & Smokers & Non-smokers & Total \\
\hline Protective responder & $19(11.9 \%)$ & $141(88.1 \%)$ & 160 \\
\hline Non protective responder & $29(72.5 \%)$ & $11(27.5 \%)$ & 40 \\
\hline Total & $48(100 \%)$ & $118(100 \%)$ & $200(100 \%)$ \\
\hline
\end{tabular}

$\mathrm{p}$ value by Chi square test is less than 0.0001

Table-3 depicts relationship of BMI with anti-HBs status. Higher BMI is associated with greater number of nonprotective responders, which is statistically significant ( $\mathrm{p}$ value less than 0.0001 ).

Table-3: Body mass index and anti-HBs status.

\begin{tabular}{|c|c|c|c|}
\hline Anti-HBs status & BMI < 25 & BMI > 25 & Total \\
\hline Protective responder & $142(88.7 \%)$ & $18(11.3 \%)$ & 160 \\
\hline Non protective responder & $04(10 \%)$ & $36(90 \%)$ & 40 \\
\hline Total & $146(100 \%)$ & $54(100 \%)$ & $200(100 \%)$ \\
\hline
\end{tabular}

$\mathrm{p}$ value by Chi square test is less than 0.0001

Figure-2 shows highest number of protective responders in initial 5years of post vaccination duration and least protective responders are observed in $>10$ years post vaccination duration, indicating decline in antibody response over time.

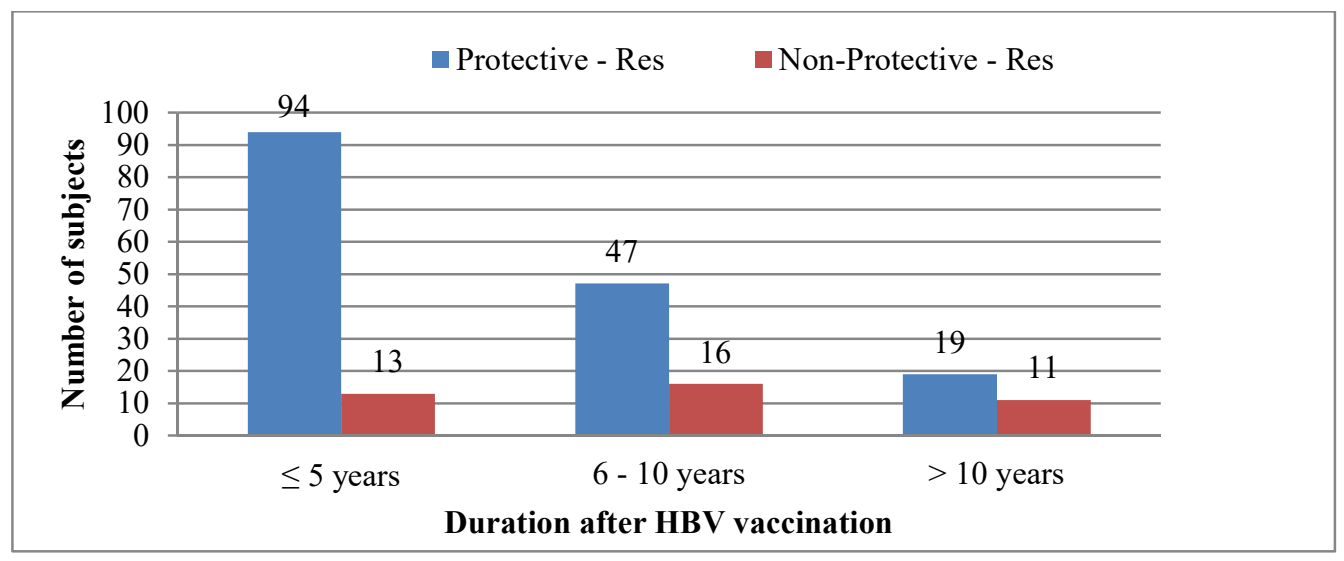

Figure-2: Duration after HBV vaccination and Anti-HBs status.

\section{Discussion}

Vaccination is the most effective prevention method for Hepatitis B. Since the 1980s, primary HBV immunization has been implemented to reduce HBV transmission and has shown high efficacy [21]. Seroprotection against $\mathrm{HBV}$ infection is defined as having an anti-HBs level of $\geq 10 \mathrm{mIU} / \mathrm{mL}$ after having received a complete immunization schedule [14]. Immunity against HBV provides protection against infection which is directly related to the peak production of antiHBs after primary vaccination. Additionally, protection against disease is offered by immune memory cells, which persists even after disappearance of anti-HBs [21]. In the present study, out of total 200 subjects, 160 $(80 \%)$ were protective responders and $40(20 \%)$ were non protective responders, post HBV immunization. Although the percentage of female protective responders was greater $(85.5 \%)$ compared to male protective responders $(75.9 \%)$, the association of antiHBs status and gender was not statistically significant. Ashmaki et al, Chaudhari et al observed that anti-HBs titer due to gender factor was not statistically significant [22,23]. Also research studies have reported increased 


\section{Original Research Article}

percentage of non-protective responders among males as compared to females [24,25]. Smoking and certain genetic factors have been proposed as probable reasons for a poor immune response to HBV immunization in men $[17,18]$. In the present study, maximum nonprotective responders were constituted by subjects above 60 years age group, whereas least by less than 20 years age group.

Maximum positive responders were seen in age group of 21-40 years. Similarly, Aghakhani et al studied persistence of anti-HBs among vaccinated children and concluded that vaccine-induced anti-HBs titer decline or remain undetectable with increase in age [26]. Age associated changes in humoral and cellular immune function is a determining factor for poor immune response to vaccination. Sero-protection declines among individuals above 40 years compared to those less than 40 years [27]. This underlines the importance of $\mathrm{HBV}$ vaccination at the earliest for better immunogenicity and protection for high risk group especially among health care workers.

In the current study, $60.4 \%(29 / 48)$ smokers showed antibody titer $<10 \mathrm{mIU} / \mathrm{mL}$. This association of smoking with reduced anti HBs titer is statistically significant. This present finding is consistent with decreased antibody titer observed in smokers as compared to nonsmokers in various research studies [28,29]. Cigarette smoking is associated with range of alterations in immune function. It is well-accepted that nicotine leads to weakening of immune system[30,31].

Winter et al found that smokers who received hepatitis $B$ vaccines at 0,1 , and 6 months had lower antibody levels than nonsmokers after 3, 7, and 13 months [32]. Nejad et al also identified smoking as a significant factor associated with decreased sero-protection after HBV vaccination in Iranian healthcare workers [33]. Shaw et al also established a harmful effect of cigarette smoking on antibody response after hepatitis B vaccination. [29] Wood et al. also linked smoking as an independent risk factor for vaccine non-response [25].

In the present study, $66.6 \%$ subjects of BMI $>25$ has anti HBs titers less than $10 \mathrm{mIU} / \mathrm{ml}$, this association of higher BMI with low titer is statistically significant. Weber et al observed that antibody responses to hepatitis B vaccine were significantly reduced in obese individuals as compared with non-obese people [34]. Dinelli et al reported that the obese women who did not response to 6 doses of recombinant hepatitis B vaccine, showed sero-conversion subsequent to weight reduction [35].A suggested mechanism causing inappropriate immune responses in obese individuals may be leptininduced systemic inflammation and alterations in innate and adaptive immune responses [36].

In the present study, highest number of protective responders $(58.8 \%)$ is seen in $0-5$ years post vaccination and least protective responders $(11.9 \%)$ are observed more than 10 years post vaccination indicating decline in antibody response over a period of time. Floreani A et al evaluated the long-term persistence of seroprotection after $\mathrm{HBV}$ vaccination and concluded that rate of persistence of anti-HBs declines with increase in the duration of post vaccination period [37]. In adults, anti-HBs concentrations decrease rapidly within the first year after primary vaccination and more slowly thereafter.

A decline of titer to a level of $10 \mathrm{mIU} / \mathrm{mL}$ is seen in $7 \%-50 \%$ of vaccinated adults within 5 years after vaccination was observed [38]. Regardless of low or undetectable antibody titers years after vaccination, immune memory was confirmed in various studies [39, 40]. Therefore, CDC advised that a booster dose no longer be administered to fully vaccinated healthy subjects [14].

Limitations of present study: In the present study, the response of revaccination (second three dose schedule) was not analyzed among non-responders in the initial series of Hepatitis B vaccination. Likelihood of responding to a revaccination schedule is reported to be high among initial non responders to vaccination.

\section{Conclusion}

The present study determined immune response to hepatitis B vaccine amongst health care workers. Anti HBs levels were measured and the influence of factors like gender, age, smoking, body mass index and duration after immunization on antibody levels was analyzed. The percentage of female protective responders was greater compared to male protective responders, but the association of anti-HBs status and gender was not statistically significant.

Increase in age leads to decline of anti-HBs protective responders. Smoking and higher body mass index (BMI $>25)$ are significantly associated with inadequate anti HBs titers $(<10 \mathrm{mIU} / \mathrm{ml})$ following vaccination. The anti HBs titers show waning effect with regard to increase in post vaccination period. The highest numbers of protective responders are seen in initial 5 years of post-vaccination and least protective responders are observed in more than 10 years of postvaccination.

Pathology Update: Tropical Journal of Pathology \& Microbiology Available online at: www.medresearch.in 811 | P a g e 


\section{Original Research Article}

\section{What the study adds to the existing knowledge?}

In the context of present study, it is recommended to test anti-HBS titer after 1-2 month of last dose of vaccination to check efficacy of immunization. Further it is also recommended that non-protective responders (with titer of $<10 \mathrm{mIU} / \mathrm{ml}$ ) should be re-vaccinated with complete 3 dose series (as per CDC guidelines). Even after complete re-vaccination, if anti-HBs titer continues to remain $<10 \mathrm{mIU} / \mathrm{ml}$, then such individual is categorized as non-responders. HCW, who are nonresponders should be counseled that they are susceptible to HBV infection, in spite of vaccination.

\section{Author's contribution}

Dr. Gitanjali Kailas Badave: Conceived and designed the study, Prepared the manuscript

Priyanka Puneriya: Data collection and data analysis

Funding: No funding sources

Conflict of interest: None declared

Ethical Approval: This study was approved by the Institutional Ethics Committee

\section{References}

1.Previsani N, Lavanchy D. World Health Organization. Hepatitis B(WHO/CDS/ CSR/LYO/ 2002.2). 2002.

2. Dannetun E, Tegnell A, Torner A, Giesecke J. Coverage of hepatitis B vaccination in Swedish healthcare workers. J Hosp Infect. 2006;63(2):201-204. doi: https://doi.org/10.1016/j.jhin.2006.01.014.

3. US Public Health Service. Updated U.S. Public Health Service guidelines for the management of occupational exposures to $\mathrm{HBV}, \mathrm{HCV}$, and HIV and recommendations for post exposure prophylaxis. MMWR 2001;29:50.

4. Elavia AJ, Banker DD. Hepatitis B virus infection in hospital personnel. Nat Med J India. 1992;5(6): 265-268.

5. Kumar KA, Baghal PK, Shukla CB, Jain MK. Prevalence of hepatitis B surface antigen (HBsAg) among Health Care Workers. Indian J Comm Med. 2000; 25 (2):93-96.

6. Kalaskar A, Kumar M. Prevalence of hepatitis B and hepatitis $\mathrm{C}$ viruses among nurses and nursing students in a medical college hospital in southern Tamil Nadu, India. Int Res J Microbiol. 2012;3(1):10-13.
7. Jha AK, Chadha S, Bhalla P, Saini S. Hepatitis B infection in microbiology laboratory workers: prevalence, vaccination, and immunity status. Hepat Res Treat. 2012; 2012: 520362. doi: 10.1155/2012/ 52036

8. Laharia C, Subramanya C, Sosler S. An assessment of introduction of hepatitis B vaccine in India: Lessons for roll out and scale up of new vaccines in immunization programs. Indian J Public Health. 2013; 57 (1):8-14. doi: 10.4103/0019-557X.111357.

9. WHO Department of Immunization, Vaccines and Biologicals. 2009. World Health Organization (WHO) Vaccine Preventable Diseases: Monitoring System. 2009 Global Summary. WHO Geneva, Switzerland.

10. Beasley, R. Palmer \& WHO Expanded Programme on Immunization. (1988). Hepatitis B: immunization strategies / R. Palmer Beasley. World Health Organization. Available at https:/apps.who.int/iris/ handle / 10665/60119.

11. Pati NT, Sethi A, Agrawal K, Agrawal K, Kumar G $\mathrm{T}$, Kuma $\mathrm{M}$. et al. Low level of awareness, vaccine coverage, and the need for booster among health care workers in tertiary care hospitals in India. J Gastroenterol Hepatol. 2008; 23(11):1710-1715. doi:10. 1111/j.1440-1746.2008.05483.x.

12. Shrestha SK, Bhattarai MD. Study of hepatitis B among different categories of health care workers. J Coll Physicians Surg Pak. 2006;16(2):108-111. doi: 2. 2006 /JCPSP.108111.

13. Shefer A, Atkinson W, Friedman C, Kuhar DT, Mootrey G, Bialek SR, et al Immunization of Health CareWorkers, "Recommendation of advisory committee on immunization practice (ACIP) and the Hospital Infection Control Practice advisory committee (HICPAC)," MMWR, Recommendation and Report. 1997; 46:1-42.

14. Mast EE, Weinbaum CM, Fiore AE, Alter MJ, Bell BP, Finelli L, et al. A comprehensive immunization strategy to eliminate transmission of hepatitis B virus infection in the United States: recommendations of the Advisory Committee on Immunization Practices (ACIP) part II: immunization of adults. MMWR Recomm Rep. 2006;55(RR-16):1-33; quiz CE1-4.

15. Jack AD, Hall AJ, and Maine N, Mendy M, Whittle HC. What level of hepatitis B antibody is protective? J Infect Dis. 1999;179(2):489-492. doi: https://doi.org/10. $1086 / 314578$

Pathology Update: Tropical Journal of Pathology \& Microbiology Available online at: www.medresearch.in 812 | P a g e 


\section{Original Research Article}

16. Alikasifoglu M, Cullu F, Kutlu T, Arvas A, Taştan Y, Erginöz E, et al. Comparison study of the immunogenicity of different types and dosages of recombinant hepatitis B vaccine in healthy neonates. J Trop Pediatr. 2001;47(1):60-62. doi: 10.1093/tropej/ 47. 1.60 .

17. Tripathy S, Sathi HC, Puspa SS, Shankar R, Singh VK. Study of immune response after hepatitis B vaccination in medical students and healthcare workers. Ind J Prevent Soc Med. 2011 ;42: 315321.

18. Nashibi R, Alavi SM, F. Yousefi F, Salmanzadeh S, Moogahi S, Ahmadi F et al. Post-vaccination immunity against hepatitis B virus and predictors for nonprotective responders among medical staff. Jundishapur J Microbiol. 2015;8(3): e19579. doi: 10.5812/ jjm. 19579.

19. Francis DP, Hadler SC, Thompson SE, Maynard JE, Ostrow DG, Altman N, et al. The prevention of hepatitis B with vaccine: report of the Centers for Disease Control multicenter efficacy trial among homosexual men. Ann Intern Med. 1982;97(3):362-366. doi: 10.7326/0003-4819-97-3-362.

20. CDC. Updated US Public Health Service Guidelines for the Management of Occupational Exposure to HBV, $\mathrm{HCV}$ and HIV and Recommendation for Post exposure Prophylaxis. MMWR 2001;50(RR11):1-42.

21. Poovorawan Y, Sanpavat S, Pongpunglert W, Chumdermpadetsuk S, Sentrakul P, Vandepapelière P, et al. Long-term efficacy of hepatitis $B$ vaccine in infants born to hepatitis B e antigen-positive mothers. Pediatr Infect Dis J. 1992;11(10):816-821. doi: 10 . 1097/00006454-199210000-00002.

22. Acchammachary AA, Ubale M, Belurkar DD, Bhave PP, Malgaonkar AA, Kartikeyan S. A crosssectional study of post-vaccination anti-HBs titer and knowledge of hepatitis B infection amongst medical students in a metropolitan city. Int $\mathrm{J}$ Res Med Sci. 2017;5(1):83-88. doi: http://dx.doi.org/10.18203/23206012.ijrms20164528.

23. Chaudhari C, Bhagat M, Shah T, Misra R. Antibody to Hepatitis B Surface Antigen in Vaccinated Health Care Workers. Med J Armed Forces India. 2008;64 (4):329-332. doi: 10.1016/S0377-1237(08) 80013-5.

24. Zeeshan M, Jabeen K, Ali AN, Ali AW, Farooqui SZ, Mehraj V, Zafar A. Evaluation of immune response to Hepatitis B vaccine in health care workers at a tertiary care hospital in Pakistan: an observational prospective study. BMC Infect Dis. 2007;7(1):120. doi: 10.1186/1471-2334-7-120.

25. Wood RC, Macdonald KL, White KE, Hedberg CW, Hanson M, Osterholm MT. Risk factors for lack of detectable antibody following hepatitis B vaccination of Minnesota health care workers. J Am Med Assoc. 1993; 270 (24):2935-2939. doi:10.1001/jama.1993.0351024 0047030 .

26. Aghakhani A, Banifazl M, Izadi N, McFarland W, Sofian M, Khadem-Sadegh A et al. Persistence of antibody to hepatitis B surface antigen among vaccinated children in a low hepatitis $B$ virus endemic area. World J Pediatr 2011; 7(4):358-360. doi: https:// doi.org/10.1007/s12519-011-0286-4.

27. Wick G, Grubeck-LoebensteinB. The aging immune system: primary and secondary alterations of immune reactivity in the elderly. Exp Gerontol. 1997; 32 (4-5): 401-413. doi: 10. 1016/ s0531- 5565 (96) 001 52-0.

28. Bock H, Kruppenbacher J, Sanger R. Immunogenicity of a recombinant hepatitis $B$ vaccine in adults. Arch Intern Med. 1996;156(19):2226-2231. doi:10. 1001/ archinte. 1996.00440180088011.

29. Shaw FE, Guess HA, Roets JM. The effect of anatomic injection site, age and smoking on the immune response to hepatitis B Vaccination. Vac. 1989; 7 (5): 425-430. doi: 10.1016/0264-410x (89) 90157-6.

30. Arcavi L, N. L. Benowitz. Cigarette smoking and infection. Arch Intern Med. 2004;164(20):2206-2216. doi: 10.1001/archinte.164.20.2206.

31. Sopori M. 2002. Effects of cigarette smoke on the immune system. Nat Rev Immunol. 2002;2(5):372-377. doi: $10.1038 /$ nri803.

32. Winter A. P., E. A. Follett, J. McIntyre, J. Stewart, I. S. Symington. 1994. Influence of smoking on immunological responses to hepatitis B vaccine.Vac. 1994; 12(9):771-772. doi: https://doi.org/10.1016/0264410X(94)90283-6.

33. Nejad EM, Jafari S, Rabirad N. Hepatitis B virus antibody levels in high-risk health care workers. Hepat Mon. 2011; 11 (8): 662-663. doi: 10.5812/kowsar. 1735143 X.707.

Pathology Update: Tropical Journal of Pathology \& Microbiology Available online at: www.medresearch.in 813 | P a g e 
34. Weber DJ, Rutala WA, Samsa GP, Bradshaw SE, Lemon SM. Impaired immunogenicity of hepatitis B vaccine in obese person.N Engl J Med. 1986;314 (21):1393. doi: 10.1056/NEJM198605223142120.

35. Dinelli MI, Moraes-Pinto MI. Seroconversion to hepatitis $\mathrm{B}$ vaccine after weight reduction in obese nonprotective responder. Rev Inst Med Trop Sao Paulo. 2008; 50 (2): 129-130. doi: 10.1590/ s003646652008000200013.

36. Papathanassoglou E, El-Haschimi K, Li XC, Matarese G, Strom T, Mantzoros C. Leptin receptor expression and signaling in lymphocytes:kinetics during lymphocyte activation, role in lymphocyte survival, and response to high fat diet in mice. J Immunol .2006;176 (12):7745-7752. doi: 10.4049/jimmunol.176.12.7745.

37. Floreani A, Baldo V, Cristofoletti M, Renzulli G, Valeri A, Zanetti C, et al. Long-term persistence of
anti-HBs after vaccination against HBV: an 18 year experience in health care workers. Vac. 2004; 22(5-6): 607-610. doi: https://doi.org/10. 1016/j.vaccine. 2003. 09.001 .

38. Plotkin S, Orsenstein W, Offit P. Vaccines. Philadelphia: Elsevier, 2008.

39. Bauer T, Jilg W. Hepatitis B surface antigenspecific $\mathrm{T}$ and $\mathrm{B}$ cell memory in individuals who had lost protective antibodies after hepatitis B vaccination. Vac.2006;24(5):572-577.doi: https://doi.org/10. 1016/j. vaccine. 2005.08 .058

40. Wainwright RB, McMahon BJ, Bulkow LR, Parkinson AJ, Harpster AP. Protection provided by hepatitis B vaccine in a Yupik Eskimo population. Seven-year results. Arch Intern Med. 1991;151(8): 1634-1636. doi: 10.1001/archinte.151.8.1634.

\section{How to cite this article?}

Badave G.K, Puneriya P. Assessment of immune response to Hepatitis B vaccine by estimation of anti - HBs antibody titer among immunized health care workers. Trop J Path Micro 2019;5(10):807-814.doi:10.17511/jopm.2019.i10.09. 